\title{
A Simple Method to Optimize the Effectiveness of Chemotherapy: Modulation of Glucose Intake During Chemotherapy
}

\author{
PHILIPPE ICARD ${ }^{1,2}$, BERNARD TEBOUL $^{3,4}$ and PHILIP EL BAZE ${ }^{4}$ \\ ${ }^{1}$ Normandie University, UNICAEN, INSERM U1199 (BioTICLA), Centre François Baclesse \\ "Biology and Innovative Therapeutics for Locally Agressive Cancers" (BioTICLA), Caen, France; \\ ${ }^{2}$ Thoracic Surgical Department, CHU Pasteur, Nice, France; \\ ${ }^{3}$ Geriatrician, Nursing Home «La Colline» Casip-Cojasor, Nice, France; \\ ${ }^{4}$ Center for Healthcare Innovation and Uses (CIU-Santé), \\ University Hospital of Nice, Cimiez Hospital, Nice, France
}

\begin{abstract}
Background/Aim: Cancer cells consume high amounts of glucose to produce ATP and molecules entering biosynthesis. Numerous experimental studies have demonstrated that glucose deprivation and/or glycolysis inhibition arrest cancer cell growth and may increase the efficiency of cytotoxic drugs. In contrast, increasing glycolysis in tumor-infiltrating lymphocytes (TILs) activates these cells that destroy cancer cells. We propose to increase the efficiency of chemotherapy by modulating glucose intake during the course of chemotherapy. Materials and Methods: Glucose and caloric intake should be drastically reduced the day before and during chemotherapy administration to deprive cancer cells of ATP and molecules required to repair cytotoxic lesions. Few hours after chemotherapy, glucose and caloric intake should be drastically increased for few days to promote the activation of TILs that reinforce the destruction of cancer cells. Results: This strategy could improve the results of chemotherapy by first enhancing cytotoxic stress against tumor cells and then promoting activation of the anti-cancer immune response. Conclusion: The modulation of glucose intake during chemotherapy should be tested clinically. The proposed scheme is simple, surely easier to follow than a strict chronic diet, and should avoid weight loss.
\end{abstract}

Correspondence to: Philippe Icard, Normandie University, UNICAEN, INSERM U1199 (BioTICLA), Centre François Baclesse "Biology and Innovative Therapeutics for Locally Agressive Cancers" (BioTICLA), Caen, France. E-mail: philippe.icard@hotmail.fr

Key Words: Warburg effect, glucose, diet, chemotherapy, radiotherapy, immunotherapy.
Cancer cells consume large amounts of glucose (10 to 15 times more than normal cells) in order to produce molecules (ribose, serine), needed for biosynthesis and replication (1, 2 ). At the same time, tumor cells produce lactic acid, either because they lack oxygen and/or because they down-regulate their mitochondria to reduce the production of molecules (citrate, $\mathrm{CO}_{2}$, ATP, and reactive oxygen species (ROS)) in adequate range for proliferation (3-6). Due to the involvement of the "Warburg effect", a large part of the pyruvate no longer enters the tricarboxylic (TCA) cycle to produce $\mathrm{CO}_{2}$ and ATP, but is instead transformed into lactic acid. Since glycolysis can deliver ATP up to 100-times more rapidly than mitochondria (7), cancer cells may use this pathway to rapidly adjust their concentration of ATP into an adequate range for active proliferation. This "disconnection" between glycolysis and mitochondria is promoted by hypoxia-inducible factor (HIF) (8) and supported by various oncogenes and aberrant signaling pathways, in particular Myc, K-ras, and STAT-3 (9-12).

Numerous experimental studies have shown that strategies promoting the inhibition of glycolysis and/or the deprivation of glucose, arrest cancer cell growth while increasing sensitivity to chemotherapy (13-15). It is noteworthy that the disconnection of glycolysis from the mitochondria can be partially compensated with the increase of glutamine consumption, especially when glucose is limited $(9,16)$. The waste-products rejected by cancer cells in their microenvironment, such as lactate, promote cancer cell invasiveness, in particular through inhibition of the immune response (17-19). Importantly, recent studies have shown that cancer cells escape immune destruction, because they divert glucose for their own benefit (20). This process inhibits the use of glucose by tumor-infiltrating lymphocytes (TILs) 


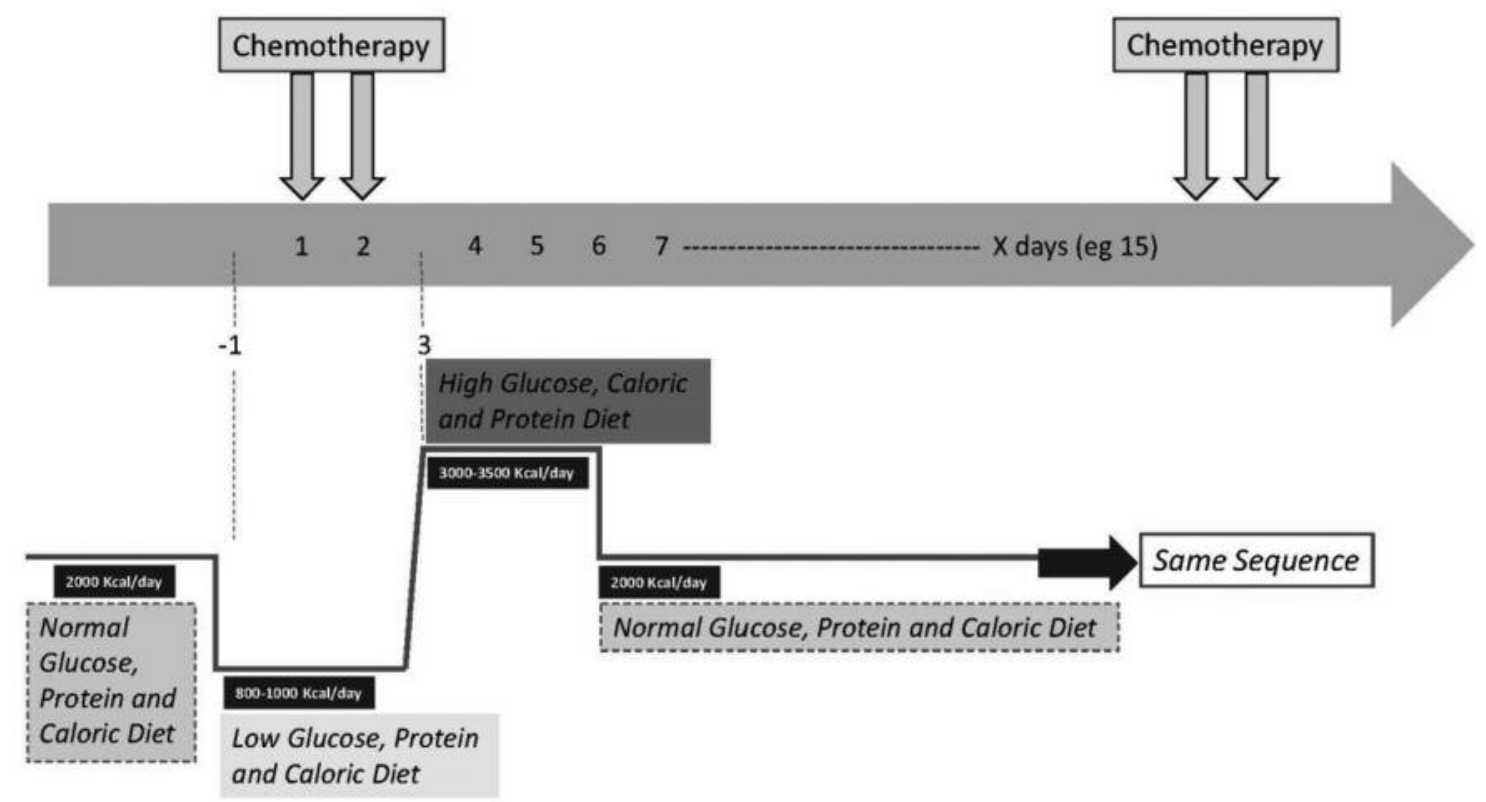

Figure 1. A protocol of diet could be the following: i) First, a severe restriction in glucose and proteins with high caloric restriction (800-1,000 Kcal/day) beginning the day before chemotherapy and finishing in the hours following drug administration; ii) then, a high intake of glucose and proteins (3,0003,500 Kcal/day) during the next 3 days, in order to promote the activation of immune cells, destroying cancer cells.

promoting their inactivation. In contrast, glycolysis activates TILs which rapidly multiply and destroy cancer cells through acute inflammation and secretion of interferon $\gamma(20-22)$. Current immunotherapy is based on the competition between cancer cells and TILs: PD-1 ligand (PD-L1) stimulates glycolysis in cancer cells through the activation of the Akt/mTOR pathway $(20,23)$. Therefore, the inhibition of PD-L1 stimulates glycolysis in cytotoxic $\mathrm{CD}^{+} \mathrm{T}$ lymphocytes, promoting acute inflammation and secretion of interferon $\gamma(20,23)$. Furthermore, competitive uptake of glucose by activated T cells can starve Dendritic cells (DCs), and promote the stimulation of pro-inflammatory DCs which enhance the immune response (24).

Thus, as demonstrated in experimental models (13-15), the efficacy of chemotherapy drugs could be increased by depriving cancer cells of the energy and molecules needed to repair cytotoxic lesions, whereas $\mathrm{CD} 8^{+} \mathrm{T}$ cells destroying cancer cells could be stimulated by increasing their glucose utilization (20-23). Thus, an optimal metabolic strategy should consist in starving the cancer cells in glucose while increasing the consumption of glucose in the $\mathrm{CD}^{+} \mathrm{T}$ lymphocytes. We propose here a simple method aimed at this dual objective of increasing the effectiveness of chemotherapy and promoting an acute activation of the immune system destroying cancer cells. This method relies on modulating the intake of glucose and calories during chemotherapy.

\section{Materials and Methods}

As consequence of these experimental facts and explanations, we propose a simple method to improve the efficiency of cytotoxic drugs: - first, the intake of sugar and proteins should be drastically reduced the day before, during the administration of chemotherapy to deprive cells of molecules (glucose, glutamine) and ATP required for repairing cytotoxic drug damages, and to activate dendritic cells; -few hours after the end of chemotherapy administration, the intake of glucose and proteins should be drastically increased for 3-4 days to activate the acute immune response to reinforce the cytotoxicity of chemotherapy drugs.

To test this hypothesis, we propose a protocol of diet that could be: (i) a severe restriction in glucose and proteins with severe caloric restriction (800-1,000 Kcal/day) that begins the day before chemotherapy and finishes in the hours following drug administration; - then, a high intake of glucose and proteins $(3,000-$ $3,500 \mathrm{Kcal} /$ day) should be implemented during the next 3 days, in order to promote the activation of TILs, destroying cancer cells. Apart this short period of 6 to 7 days surrounding chemotherapy, the patient has no special diet to follow (Figure 1).

\section{Results}

To confirm or refute this hypothesis, clinical studies should compare the administration of chemotherapy (for example that of cisplatin, one of most frequently used drugs in cancer therapy), with or without the association of this sequential diet protocol modulating the intake of glucose and proteins during the course of chemotherapy as aforementioned. 
Knowing that the metabolic response can be rapidly evaluated by positron emission tomography (PET scan) in the days following cytotoxic drugs administration (25), this examination should be advantageously performed within the week after the end of the protocol, to make a comparison between the groups.

\section{Discussion}

If our hypothesis is confirmed, the modulation of glucose and caloric intake during and after chemotherapy can be a new strategy for increasing the action of cytotoxic drugs, while promoting the activation of immune cells. The dietary scheme we proposed is simple and likely much easier to follow than a chronic diet such as a ketogenic diet (for review see 26), because it is sequential and intermittent. Although duration of the first hypocaloric phase is brief ( 2 or 3 days), such short term fasting can be efficient to reduce side effects of chemo and radiation therapy while improving their results, as demonstrated in animal models (26-30). These beneficial effects would be mediated in part by hypoglycemia and reduction in insulin-like growth factor 1 (IGF-1) level (31, 32). Because the second phase of our diet protocol is hypercaloric, weight loss should be avoided or limited while promoting the immune response against cancer. This stimulation of anti-tumoral immunity is surely a key element of an effective therapeutic strategy, as demonstrated by the better prognosis of cancers with activated TILs $(33,34)$, while it could also improve the efficiency of immunotherapy.

Finally, apart from the short period of time surrounding chemotherapy (approximately 6 days), the patient has no special diet to follow. A great advantage of this intermittent diet should be the maintenance of a stable weight. Case studies should be undertaken to verify the accuracy of the concept, while use of PET may help determine the level of caloric intake that has a favorable impact on the efficacy of chemotherapy, maybe even able to overcome resistance to chemotherapy in some cases. This new strategy, simple and inexpensive, aimed both at increasing the effectiveness of chemotherapy while strengthening the immune response against tumor cells, could have a major influence in the field of cancer treatment.

\section{Acknowledgements}

The Authors would like to thank Eric Williamson for his assistance in language editing English assistance and Oriane Rein Dubuisson for their technical assistance in the realization of the figure.

\section{References}

1 Vander Heiden MG, Cantley LC and Thompson CB: Understanding the Warburg effect: the metabolic requirements of cell proliferation. Science 324: 1029-1033, 2009.

2 Icard $\mathrm{P}$ and Lincet $\mathrm{H}$ : A global view of the biochemical pathways involved in the regulation of the metabolism of cancer cells. Biochim Biophys Acta 1826: 423-433, 2012.
3 Porporato PE, Dhup S, Dadhich RK, Copetti T and Sonveaux P: Anticancer targets in the glycolytic metabolism of tumors: a comprehensive review. Front Pharmacol 49: 1-18, 2011.

4 Koppenol WH, Bounds PL and Dang CV: Otto Warburg's contributions to current concepts of cancer metabolism. Nat Rev Cancer 11: 325-337, 2011.

5 Icard $\mathrm{P}$ and Lincet $\mathrm{H}$ : The reduced concentration of citrate in cancer cells: an indicator of cancer aggressiveness and a possible therapeutic target". Drug Resist Updat 29: 47-53, 2016.

6 Zhou W, Liotta LA and Petricoin EF: The Warburg Effect and Mass Spectrometry-based Proteomic Analysis. Cancer Genomics Proteomics 14: 211-218, 2017.

7 Pfeiffer T, Schuster S and Bonhoeffer S: Cooperation and competition in the evolution of ATP-producing pathways. Science 292: 504-507, 2001.

8 Semenza GL: HIF-1: upstream and downstream of cancer metabolism. Curr Opin Genet Dev 20: 51-56, 2010.

9 Dang CV, Kim JW, Gao P and Yustein J: The interplay between MYC and HIF in cancer. Nat Rev Cancer 8: 51-56, 2008.

10 Gaglio D, Metallo CM, Gameiro PA, Hiller K, Danna LS, Balestrieri C, Alberghina L, Stephanopoulos G and Chiaradonna F: Oncogenic K-Ras decouples glucose and glutamine metabolism to support cancer cell growth. Mol Syst Biol 7: 523, 2011.

11 Margetis N, Kouloukoussa M, Pavlou K, Vrakas S and MariolisSapsakos T: K-ras Mutations as the Earliest Driving Force in a Subset of Colorectal Carcinomas. In Vivo 31: 527-542, 2017.

12 Akiyama Y, Iizuka A, Kume A, Komiyama M, Urakami K, Ashizawa T, Miyata H, Omiya M, Kusuhara M and Yamaguchi $\mathrm{K}$ : Effect of STAT3 inhibition on the metabolic switch in a highly STAT3-activated lymphoma cell line. Cancer Genomics Proteomics 12: 133-142, 2015.

13 Zhang X, Varin E, Allouche S, Lu Y, Poulain L and Icard P: Effect of citrate on malignant pleural mesothelioma cells: a synergistic effect with cisplatin. Anticancer Res 29: 1249-1254, 2009.

14 Icard P, Zhang X, Varin E, Lincet H and Poulain L: Experimental results using 3-bromopyruvate in mesothelioma: in vitro and in vivo studies. J Bioenerg Biomembr 44: 81-90, 2012.

15 Zhou Y, Bollu LR, Tozzi F, Ye X, Bhattacharya R, Gao G, Dupre E, Xia L, Lu J, Fan F, Bellister S, Ellis LM and Weihua Z: ATP citrate lyase mediates resistance of colorectal cancer cells to SN38. Mol Cancer Ther 12: 2782-2791, 2013.

16 Deberardinis RJ and ChengT: Q's next: the diverse functions of glutamine in metabolism, cell biology and cancer. Oncogene 29: 313-324, 2010.

17 Dhup S, Dadhich RK, Porporato PE and Sonveaux P: Multiple biological activities of lactic Acid in cancer: influences on tumor growth, angiogenesis and metastasis. Curr Pharm Des 18: 13191330, 2012.

18 Pérez-Escuredo J, Dadhich RK, Dhup S, Cacace A, Van Hée VF, De Saedeleer CJ, Sboarina M, Rodriguez F, Fontenille MJ, Brisson L, Porporato PE and Sonveaux P: Lactate promotes glutamine uptake and metabolism in oxidative cancer cells. Cell Cycle 15: 72-83, 2016.

19 Icard P, Kafara P, Steyaert JM, Schwartz L and Lincet H: The metabolic cooperation between cells in solid cancer tumors. Biochim Biophys Acta 1846: 216-225, 2014.

20 Sukumar M, Roychoudhuri R and Restifo NP: Nutrient competition: a new axis of tumor immunosuppression. Cell 162: 1206-1208, 2015. 
21 Wherry EJ: T cell exhaustion. Nat Immunol 12: 492-499, 2011. 22 Crespo J, Sun H, Welling TH, Tian Z and Zou W: T cell anergy, exhaustion, senescence, and stemness in the tumor microenvironment. Curr Opin Immunol 25: 214-221, 2013.

23 Chang CH, Qiu J, O’Sullivan D, Buck MD, Noguchi T, Curtis JD, Chen Q, Gindin M, Gubin MM, van der Windt GJ, Tonc E, Schreiber RD, Pearce EJ and Pearce EL: Metabolic competition in the tumor microenvironment is a driver of cancer progression. Cell 162: 1229-124, 2015.

24 Lawless SJ, Kedia-Mehta N, Walls JF, McGarrigle R, Convery O, Sinclair LV, Navarro MN, Murray J and Finlay DK: Glucose represses dendritic cell-induced $\mathrm{T}$ cell responses. Nat Commun 8: 15620,2017

25 Nahmias C, Hanna WT, Wahl LM, Long MJ, Hubner KF and Townsend DW: Time course of early response to chemotherapy in non-small cell lung cancer patients with $18 \mathrm{~F}-\mathrm{FDG}$ PET/CT. J Nucl Med 48: 744-751, 2007.

26 O'Flanagan $\mathrm{CH}$, Smith LA, McDonell SB and Hursting SD: When less may be more: calorie restriction and response to cancer therapy. BMC Med 15: 106, 2017.

27 Martina D’Aronzo, Manlio Vinciguerra, Tommaso Mazza, Concetta Panebianco, Chiara Saracino, Stephen P. Pereira, Paolo Graziano and Valerio Pazienza: Fasting cycles potentiate the efficacy of gemcitabine treatment in in vitro and in vivo pancreatic cancer models. Oncotarget 6: 18545-18557, 2015.

28 Di Biase S, Shim HS, Kim KH, Vinciguerra M, Rappa F, Wei M, Brandhorst S, Cappello F, Mirzaei H, Lee C and Longo VD: Fasting regulates EGR1 and protects from glucose- and dexamethasone-dependent sensitization to chemotherapy. PLoS Biol 15: e1002603, 2017.
29 Lo Re O, Panebianco C, Porto S, Cervi C, Rappa F, Di Biase S, Caraglia M, Pazienza V and Vinciguerra M: Fasting inhibits hepatic stellate cells activation and potentiates anti-cancer activity of Sorafenib in hepatocellular cancer cells. J Cell Physiol, 2017. doi: 10.1002/jcp.25987. [Epub ahead of print] [Epub ahead of print]

30 Raffaghello L, Lee C, Safdie FM, Wei M, Madia F, Bianchi G and Longo VD: Starvation-dependent differential stress resistance protects normal but not cancer cells against high-dose chemotherapy. Proc Natl Acad Sci USA 105: 8215-8220, 2008.

31 Lee $\mathrm{C}$ and Longo VD: Fasting vs dietary restriction in cellular protection and cancer treatment: from model organisms to patients. Oncogene 30: 3305-3316, 2011.

32 Safdie F, Brandhorst S, Wei M, Wang W, Lee C, Hwang S, Conti PS, Chen TC and Longo VD: Fasting enhances the response of glioma to chemo- and radiotherapy. PLoS One 7: e44603, 2012.

33 Reissfelder C, Stamova S, Gossmann C, Braun M, Bonertz A, Walliczek U, Grimm M, Rahbari NN, Koch M, Saadati M, Benner A, Büchler MW, Jäger D, Halama N, Khazaie K, Weitz $\mathrm{J}$ and Beckhove P: Tumor-specific cytotoxic T lymphocyte activity determines colorectal cancer patient prognosis. J Clin Invest 125: 1364, 2015.

34 Lee WS, Kang M, Baek JH, Lee JI and Ha SY: Clinical impact of tumor-infiltrating lymphocytes for survival in curatively resected stage IV colon cancer with isolated liver or lung metastasis. Ann Surg Oncol 20: 697-702, 2013.

Received July 4, 2017

Revised July 27, 2017

Accepted August 2, 2017 